\title{
Pemanfaatan Bahan Bio-anorganik untuk Memproduksi Biomassa Hijauan Pakan dan Inokulan Fungi Mikoriza Arbuskula
}

\author{
Bio-Inorganic Materials for Production of Forage Legume and Arbuscular \\ Mycorrhizal Fungi Inoculant
}

\author{
A. D. Nusantara ${ }^{\text {* \#, C. Kusmana }}{ }^{\text {\# }}$, I. Mansur ${ }^{\text {\# }}$, L. K. Darusman ${ }^{\text {§ }}$, \& Soedarmadie $\$$ \\ aProgram Studi Ilmu Pengetahuan Kehutanan, Sekolah Pascasarjana, Institut Pertanian Bogor \\ ${ }^{b}$ Departemen Ekologi Hutan, Fakultas Kehutanan, Institut Pertanian Bogor \\ 'Departemen Silvikultur, Fakultas Kehutanan, Institut Pertanian Bogor \\ \#Jln. Lingkar Akademik, Kampus IPB Darmaga, Bogor 16680 \\ ${ }^{d}$ Departemen Kimia, Fakultas Matematika dan Ilmu Pengetahuan Alam, Institut Pertanian Bogor \\ e Departemen Ilmu Nutrisi dan Teknologi Pakan, Fakultas Peternakan, Institut Pertanian Bogor \\ $\S$ Jln. Agatis, Kampus IPB Darmaga, Bogor 16680 \\ (Diterima 06-07-2010; disetujui 04-12-2010)
}

\begin{abstract}
Inoculant production of arbuscular mycorrhizal fungi (AMF) has a vital role in sustaining of higher forage legume production. Currently, it is important to find the alternative materials that can be used as sources of phosphorus due to the need of lower cost, environmentaly friendly, and easily available. Bone meal and rock phosphate are some of the bio-inorganic sources that can be used as a phosphorus source for producing biomass of forage legume and AMF's inoculant production. A glasshouse experiment was conducted to determine the effectiveness of different type of bioinorganic materials as a fertilizer to increase forage legume biomass and for specific AMF's inoculant production. The experiment was arranged in a factorial randomized block design with two factors, i.e. type of AMF's species (Glomus etunicatum NPI-126 and Acaulospora tuberculata INDO-2) and type of bio-inorganic materials (artifical fertilizer solution as a control, SP36, rock phosphate, and bone meal). Results showed that G. etunicatum gave better result in terms of host gowth, root colonization and spore production compare to $A$. tuberculata. Bone meal was better a phosphorus source for AMF's inoculant production instead of artifical fertilizer or other bio-anorganic sources. In conclusion, milled bone meal has a good phosphorus source for AMF's (G. etunicatum) inoculant production
\end{abstract}

Keywords: G. etunicatum, A. tuberculata, P. phaseoloides, bone meal, inoculant production

\section{PENDAHULUAN}

Fungi mikoriza arbuskula (FMA) merupakan fungi Glomeromycetes yang diketahui mampu membantu meningkatkan produktivitas hijauan pakan ternak. Kombinasi jenis FMA, jenis tanaman inang, dan sumber hara P diketahui mempengaruhi efektivitas FMA dalam meningkatkan produktivitas hijauan pakan ternak. Karti (2004) melaporkan bahwa inokulasi FMA isolat campuran (mycofer) berpengaruh nyata meningkatkan bobot kering pucuk, luas daun dan laju transpirasi rumput Setaria splendida Stapf. Widiastuti \& Suharyanto

\footnotetext{
* Korespondensi:

Jurusan Budidaya Pertanian, Fakultas Pertanian Universitas Bengkulu

Jln. Raya Kandang Limun, Bengkulu

Telp. 0736-21170; e-mail: abimanyu.dn@gmail.com
}

(2007) melaporkan bahwa FMA jenis Acaulospora tuberculata dapat meningkatkan produksi biomassa dan serapan hara N, P, dan K pada Calopogonium caeroleum Benth dan Centrosema pubescens Benth. Penggunaan inokulan FMA, yang tidak dilaporkan jenisnya, pada skala lapangan sekalipun tidak berhasil meningkatkan bobot kering namun meningkatkan kecernaan C. pubescens dan Pueraria phaseoloides Roxb (Lukiwati, 2007). Pengaruh positif FMA demikian disebabkan FMA mampu membantu tanaman menangkal berbagai cekaman biotik dan abiotik (Smith \& Read, 2008). Berdasarkan faktor-faktor tersebut, FMA dapat dijadikan sebagai salah satu alternatif teknologi ramah lingkungan untuk meningkatkan pertumbuhan dan mutu hijauan pakan ternak pada berbagai kondisi tanah dan lingkungan.

Produksi inokulan FMA dapat dilakukan dengan cara sederhana dan mudah dilakukan, yaitu dengan kultur pot terbuka menggunakan satu atau lebih jenis FMA, 
substrat dari bahan alami misalnya zeolit, tanaman inang puero, centro, atau sorghum; dan sumber fosfor (P) dari pupuk buatan (Feldmann et al., 2009). Inokulan yang dihasilkan umumnya berbentuk campuran substrat dengan akar terkolonisasi, spora, dan hifa ekstraradikal (HE). Infektivitas, efektivitas, dan potensi inokulum FMA menentukan keberhasilan inokulasi FMA di lapangan (Feldmann et al., 2009).

Salah satu faktor yang menentukan keberhasilan produksi inokulan FMA adalah sumber hara P karena pembentukan dan perkembangan FMA dapat berkorelasi negatif atau positif dengan hara $\mathrm{P}$ bergantung kepada jenis dan stadium perkembangannya (Smith \& Read, 2008). Pemberian unsur hara $P$ dalam jumlah berlebihan dapat berpengaruh buruk terhadap pembentukan dan perkembangan FMA. Namun demikian, penggunaan bahan bio-anorganik penyedia fosfat berkelarutan rendah, misalnya batuan fosfat, kalsium fosfat, dan tepung tulang, efektif untuk memelihara FMA dan meningkatkan pertumbuhan tanaman (Nikolaou et al., 2002). Batuan fosfat dilaporkan efektif untuk meningkatkan simbiosis FMA dengan legum pakan ternak (Lukiwati, 2007). Namun demikian, belum ada informasi yang secara khusus membahas peran sumber P bio-anorganik tidak mudah larut untuk memproduksi biomassa legum pakan ternak dan inokulan FMA. Berdasarkan hal tersebut, dipandang penting untuk mengevaluasi sumber $\mathrm{P}$ yang berkelarutan rendah yang mudah didapat, murah harganya dan ramah lingkungan untuk memproduksi biomassa legum pakan ternak dan inokulan jenis FMA tertentu. Penelitian ini bertujuan untuk mendapatkan kombinasi jenis FMA dan macam bahan bio-anorganik tidak mudah larut sebagai alternatif pengganti pupuk buatan untuk memproduksi biomassa legum pakan ternak dan inokulan FMA.

\section{MATERI DAN METODE}

\section{Penyediaan Bahan}

Spora Glomus etunicatum (NPI-126) (Gle) dan $A$. tuberculata (INDO-2) (Ac) diperoleh dari Laboratorium Bioteknologi Hutan dan Lingkungan, Pusat Penelitian Sumberdaya Hayati dan Bioteknologi, IPB, dan diperbanyak dengan metoda kultur tunggal menggunakan $P$. phaseoloides sebagai tanaman inang, substrat zeolit berukuran garis tengah $1 \times 1 \mathrm{~mm}$ sampai dengan $3 \times 4$ $\mathrm{mm}$ atau lolos mata saring bergaris tengah $5 \mathrm{~mm}$, dan larutan pupuk buatan sebagai sumber hara. Tepung tulang giling diperoleh dengan cara sebagai berikut: tulang dipotong sepanjang 5-10 cm, direbus selama 2-4 jam dengan suhu $100{ }^{\circ} \mathrm{C}$, ditiriskan, dan dikeringkan, kemudian dihancurkan hingga menjadi serpihan-serpihan sepanjang 1-3 cm. Serpihan tulang direndam dalam air kapur 10\% selama 4-5 minggu dan dicuci dengan air tawar. Pemisahan gelatin dengan jalan pemanasan 3 tahap, yaitu pada suhu $60{ }^{\circ} \mathrm{C}$ selama 4 jam, suhu $70{ }^{\circ} \mathrm{C}$ selama 4 jam, dan $100^{\circ} \mathrm{C}$ selama 5 jam. Tulang dikeringkan dalam oven pada suhu $100{ }^{\circ} \mathrm{C}$, sampai kadar airnya tinggal $5 \%$ dan kemudian digiling hingga menjadi tepung. Adapun tulang bakar diperoleh dengan cara membakar potongan tulang sepanjang $5-10 \mathrm{~cm}$ selama
5-6 jam dan kemudian digiling menjadi tepung. Masingmasing tepung tulang kemudian diayak dengan mata ayakan berdiameter $0,5 \mathrm{~mm}$. Batuan fosfat diperoleh dari Laboratorium Silvikultur Fakultas Kehutanan IPB, pupuk SP36 dari toko pertanian di Dramaga. Masingmasing bahan yang digunakan memiliki karakteristik kimia yang spesifik (Tabel 1).

\section{Prosedur Percobaan}

Percobaan dilaksanakan di rumah kaca Laboratorium Silvikultur Fakultas Kehutanan IPB. Penanaman bibit $P$. phaseoloides dilaksanakan pada pot plastik wadah air mineral berukuran $240 \mathrm{ml}$ yang berisi $175 \mathrm{~g}$ zeolit sebagai medium tumbuh dan sumber hara P sesuai perlakuan. Pencampuran sumber P dengan medium tumbuh sesuai dengan perlakuan yang diuji dilakukan sebelum penanaman. Sumber hara $\mathrm{P}$ pada perlakuan kontrol diberikan dalam bentuk larutan pupuk buatan komersial dengan takaran $0,5 \mathrm{~g} /$ sebanyak $11 \mathrm{ml}$ yang diberikan setiap tiga hari sekali sampai percobaan selesai atau total sebanyak $264 \mathrm{ml}$ selama 12 minggu. Medium tumbuh, dalam keadaan basah, dilubangi dan kemudian ke dalamnya diletakkan bibit $P$. phaseoloides berukuran seragam dengan tinggi $\pm 2 \mathrm{~cm}$. Dua puluh buah spora FMA yang diuji diteteskan pada permukaan akar bibit $P$. phaseoloides. Lubang tanam kemudian ditutup kembali menggunakan zeolit. Bibit dipelihara selama 12 minggu dan selama percobaan kondisi air dipertahankan tetap lembab dengan cara penyiraman air setiap hari.

Satu pot diambil secara acak dari setiap ulangan kombinasi perlakuan pada umur 6 minggu setelah tanam (MST). Akar dipisahkan dari bagian atas tanaman untuk diamati kolonisasi mikorizanya menggunakan metode Phillips \& Hayman yang dimodifikasi dengan menggunakan larutan pewarna berupa campuran lak-

Tabel 1. Kadar hara tepung tulang, batuan fosfat, dan pupuk buatan

\begin{tabular}{|c|c|c|c|c|}
\hline \multirow{2}{*}{ Jenis hara } & \multicolumn{2}{|c|}{ Tepung tulang } & \multirow{2}{*}{$\begin{array}{l}\text { Batuan } \\
\text { fosfat }^{1}\end{array}$} & \multirow{2}{*}{$\begin{array}{l}\text { Pupuk } \\
\text { buatan }^{2}\end{array}$} \\
\hline & Giling $^{1}$ & Bakar $^{1}$ & & \\
\hline N (\%) & 1,65 & 0,33 & 0,04 & 25 \\
\hline $\mathrm{P}(\%)$ & 12,16 & 13,31 & 3,78 & 1,09 \\
\hline Nisbah N/P & 0,14 & 0,02 & 0,01 & 23 \\
\hline K (\%) & 0,16 & 0,1 & 0,15 & 6,8 \\
\hline $\mathrm{Ca}(\%)$ & 19,82 & 24,76 & 11,91 & $\mathrm{td}$ \\
\hline $\operatorname{Mg}(\%)$ & 0,46 & 0,66 & 0,19 & $\mathrm{td}$ \\
\hline $\mathrm{Fe}(\mathrm{ppm})$ & 11 & 12 & 98 & $\mathrm{td}$ \\
\hline $\mathrm{Cu}(\mathrm{ppm})$ & 42 & 295 & 8480 & $\mathrm{td}$ \\
\hline Zn (ppm) & 125 & 140 & 674 & $\mathrm{td}$ \\
\hline Mn (ppm) & 23 & 29 & 1839 & $\mathrm{td}$ \\
\hline
\end{tabular}

Keterangan:

${ }^{1}$ Hasil analisis Laboratorium Ilmu Tanah, Fakultas Pertanian IPB

${ }^{2}$ Angka yang tertera pada kemasan masing-masing adalah $25 \% \mathrm{~N}$ (4,5\% N-nitrat, 20,5\% N-urea, 5\% P2O5 dan 20\% K2O, td= tidak dinyatakan (The Hyponex Co., Inc., Copley, Ohio 44321 USA). 
togliserin (campuran gliserin teknis, asam laktat teknis, dan air destilata dengan nisbah $2: 2: 1$ ) dan larutan biru tripan 0,05\% (Biofertilizer Project Group, 2006). Kolonisasi mikoriza ditandai dengan kenampakan struktur dakhil berupa hifa, vesikel atau arbuskula di bawah mikroskop. Kolonisasi (\%) diukur berdasarkan proporsi bidang pandang bermikoriza terhadap total bidang pandang yang diamati (Biofertilizer Project Group, 2006).

Percobaan dihentikan pada umur 12 MST dan secara acak dipilih satu pot plastik untuk dibongkar. Bagian atas tanaman beserta akarnya dibawa ke laboratorium untuk diukur bobot kering dan kolonisasi mikorizanya. Bobot kering diukur pasca pengeringan dalam oven bersuhu $80{ }^{\circ} \mathrm{C}$, yaitu setelah tercapai bobot yang konstan. Tanaman pada pot plastik yang tersisa dibiarkan mengering kemudian diambil satu pot secara acak untuk dipisahkan sporanya. Pemisahan spora FMA dari medium tumbuh dilakukan dengan metode penyaringan basah menggunakan penyaring berukuran 63 $\mu \mathrm{m}$ dan $45 \mu \mathrm{m}$. Spora ditampung dalam cawan tabung sentrifusi untuk kemudian disentrifugasi dalam larutan sukrosa $60 \%$. Spora dalam tabung sentrifusi dituangkan ke penyaring dan dibilas dengan air mengalir. Spora dituangkan ke cawan petri yang bagian bawahnya bergaris dan jumlah spora dihitung di bawah mikroskop.

\section{Rancangan Percobaan dan Analisis Data}

Percobaan disusun dalam rancangan acak kelompok pola faktorial. Faktor pertama ialah jenis fungi mikoriza arbuskula (G. etunicatum NPI-126 dan A. tuberculata INDO-2). Faktor kedua ialah bahan bio-anorganik yang terdiri atas (i) kontrol (larutan pupuk Hyponex merah), (ii) pupuk SP36 (18,33 mg), (iii) batuan fosfat (BP) $(38,12 \mathrm{mg}$ dan $76,23 \mathrm{mg})$, (iv) tepung tulang bakar (TTB) $(10,82 \mathrm{mg}$ dan $21,65 \mathrm{mg})$, dan (v) tepung tulang giling (TTG) (11,85 mg dan 23,70 mg). Semua tepung tulang diberikan dengan ukuran yang seragam, yaitu < 0,5 mm. Jumlah yang diberikan tersebut setara dengan satu dan dua kali takaran larutan pupuk buatan yang digunakan sebagai kontrol yang diberikan setiap tiga hari sekali selama 12 minggu. Seluruh kombinasi perlakuan diulang tiga kali, dan setiap ulangan terdiri atas enam pot tanaman.

Data hasil pengamatan dianalisa dengan model sidik ragam (ANOVA), perbedaan antar perlakuan diuji dengan uji jarak berganda Duncan pada taraf beda nyata 5\%. Transformasi Box-Cox dilakukan terhadap data yang tidak memenuhi asumsi kenormalan galat.

\section{HASIL DAN PEMBAHASAN}

\section{Produksi Bahan Kering}

Jenis FMA, bahan bio-anorganik, dan interaksi keduanya berpengaruh sangat nyata $(\mathrm{P}<0,01)$ terhadap bobot kering akar, pucuk, dan total tanaman $P$. phaseoloides pada umur 12 MST (Tabel 2). Hal tersebut menunjukkan respon inokulasi FMA bergantung kepada bahan bio-anorganik yang digunakan sebagai sumber hara. Inokulasi FMA G. etunicatum menghasilkan bobot kering akar tanaman $P$. phaseoloides yang tertinggi, yaitu sebesar 80,77, hanya jika diberi sumber hara berupa SP36, yaitu pupuk yang bersifat lebih mudah larut dan segera tersedia untuk tanaman. Penggunaan bahan bioanorganik yang bersifat tidak mudah larut sekalipun komposisi haranya lebih lengkap (Tabel 1) ternyata tetap menghasilkan bobot kering akar yang rendah pada tanaman $P$. phaseoloides yang diinokulasi G. etunicatum maupun $A$. tuberculata. Bobot kering akar terendah pada percobaan ini, yaitu sebesar 25,07 mg, dihasilkan oleh inokulasi $A$. tuberculata yang diberi tepung tulang bakar $10,82 \mathrm{mg}$.

Kombinasi inokulasi G. etunicatum dengan SP36 atau tepung tulang giling dosis $23,70 \mathrm{mg}$ ternyata menghasilkan bobot kering pucuk yang sama tingginya dengan kombinasi $A$. tuberculata dengan tepung tulang giling dosis 11,85 $\mathrm{mg}$ atau 23,70 mg (Tabel 2). Namun demikian, hanya kombinasi G. etunicatum dengan SP36 yang menghasilkan bobot kering akar $(80,77 \mathrm{mg})$ tertinggi dan pucuk tanaman $(374,63 \mathrm{mg})$ yang tinggi atau total sebesar $455,40 \mathrm{mg}$. Bobot kering total tersebut yang paling tinggi dibandingkan dengan yang dihasilkan oleh perlakuan lain sehingga kombinasi G. etunicatum dengan SP36 terbaik untuk meningkatkan biomassa tanaman $P$. phaseoloides secara keseluruhan.

Bobot kering $P$. phaseoloides pada perlakuan kontrol lebih rendah jika dibandingkan dengan hasil penelitian Chalimah et al. (2007). Bobot kering akar dan pucuk yang dihasilkan oleh kombinasi perlakuan kontrol dengan inokulasi $A$. tuberculata pada penelitian ini masing-masing sebesar 23,93 dan $152,77 \mathrm{mg}$ atau menghasilkan bobot total tanaman sebesar 176,70 mg. Penelitian Chalimah et al. (2007) mengungkapkan bahwa perlakuan inokulasi $A$. tuberculata dan pemberian larutan Hyponex merah menghasilkan total biomassa $P$. phaseoloides umur 12 MST sebesar 1,1 g. Perbedaan hasil tersebut disebabkan Chalimah et al. (2007) menggunakan dosis pupuk sebesar 1,5 g/ dan diberikan setiap minggu atau total 18 g selama 12 minggu. Pupuk yang digunakan pada penelitian ini hanya sebesar $0,5 \mathrm{~g} /$ dan diberikan setiap 3 hari sekali atau total $12 \mathrm{~g}$ selama 12 minggu. Jumlah pupuk yang lebih banyak menjadikan pertumbuhan $P$. phaseoloides lebih baik.

Sebagai pupuk yang mudah larut, pupuk SP36 dan pupuk Hyponex merah, pada awalnya menyediakan lebih banyak unsur P ke dalam medium tumbuh untuk kemudian diserap tanaman langsung oleh akar tanaman ataupun secara tidak langsung melalui hifa FMA. Kombinasi inokulasi FMA dan pupuk Hyponex merah (kontrol) menghasilkan biomassa P. phaseolides yang lebih rendah dibandingkan yang dipasok SP36 karena Hyponex merah mengandung $\mathrm{P}$ yang lebih rendah namun dengan kadar $\mathrm{N}$ yang lebih tinggi (Tabel 1) sehingga menghasilkan kolonisasi yang tinggi pada umur 6 dan 12 MST (Tabel 3). Unsur N dilaporkan meningkatkan jumlah runner hifa FMA (Bago et al., 2004) sehingga meningkatkan alokasi karbon yang diperlukan untuk pembentukan hifa ekstraradikal dan spora FMA (Johnson et al., 2003) dan menurunkan biomassa tanaman inang (Tabel 2).

Kadar hara P yang tinggi dari SP36 menghasilkan kolonisasi G. etunicatum yang tinggi hanya pada umur 
6 MST namun kemudian tidak meningkat tajam sampai pada umur 12 MST (Tabel 3). Sebaliknya, SP36 menghasilkan kolonisasi $A$. tuberculata yang rendah pada umur 6 MST namun meningkat tajam dari 5\% menjadi $26 \%$ pada umur 12 MST sekalipun tidak setinggi yang dihasilkan oleh bahan bio-anorganik. Glomus memiliki hifa intraradikal yang lebih besar dan hifa ekstraradikal yang kurang ekstensif dibandingkan dengan Acaulospora (Dodd et al., 2000). Hifa intraradikal yang lebih besar memungkinkan lebih besarnya volume hara yang dialirkan ke bagian atas tanaman untuk pembentukan biomassa sedangkan hifa ekstraradikal yang kurang ekstensif menjadikan lebih sedikitnya aliran karbon ke rhizosfer pada tanaman yang dikolonisasi G. etunicatum dibandingkan A. tuberculata. Mayerni \& Hervani (2008) melaporkan $G$. etunicatum dan $A$. tuberculata memiliki efektivitas yang sama untuk meningkatkan pertumbuhan tanaman selasih (Ocium sanctum L.). Hal tersebut menjelaskan tanaman yang dikolonisasi G. etunicatum mampu membentuk biomassa yang lebih tinggi dibandingkan dengan yang dikolonisasi $A$. tuberculata bergantung kepada karakter kimia pupuk yang diberikan dan jenis tanaman inangnya.

Bahan bio-anorganik (tepung tulang dan batuan fosfat) mengandung unsur $\mathrm{P}$, Ca dan mikro yang jauh lebih tinggi dan unsur $\mathrm{N}$ yang lebih rendah sehingga nisbah N/P-nya juga lebih rendah dibandingkan Hyponex merah (Tabel 1). Batuan fosfat mengandung unsur $\mathrm{P}$ yang lebih rendah dan unsur mikro yang lebih tinggi, tetapi tepung tulang bakar dan giling sebaliknya. Hal tersebut menjelaskan relatif samanya biomassa tanaman $P$. phaseoloides yang dikolonisasi G. etunicatum atau $A$. tuberculata dan dipasok dengan batuan fosfat, tepung tulang bakar, dan tepung tulang giling. Peningkatan dosis batuan ketiga bahan bio-anorganik tersebut tidak berpengaruh nyata terhadap peningkatan biomassa $P$. phaseoloides. Pengolahan tepung tulang merupakan salah satu faktor yang menentukan efektivitas tepung tulang sebagai pupuk. Tepung tulang bakar merupakan hasil pembakaran pada suhu $400{ }^{\circ} \mathrm{C}$, oleh karena itu memiliki kadar bahan organik yang rendah (Warren et al., 2009) sehingga dapat diduga bahwa tepung tulang bakar memiliki karakteristik permukaan dan dinamika pelarutan dan penyediaan $\mathrm{P}$ yang berbeda dengan batuan fosfat maupun tepung tulang lainnya. Tepung tulang, tepung tulang rebus, dan tepung tulang giling menghasilkan peningkatan serapan $\mathrm{P}$ dan pertumbuhan tanaman yang ditumbuhkan dalam pot dan lapangan (Jeng et al., 2006; Romer, 2006).

Unsur P dari bahan bio-anorganik dilepaskan secara bertahap sesuai dengan kemampuan tanaman mengekskresikan asam organik atau kecepatannya membentuk simbiosis dengan FMA untuk mendapatkan $\mathrm{P}$ tersebut. Pelarutan $\mathrm{P}$ dari tepung tulang dilaporkan terjadi pada 20 hari pertama (Warren et al., 2009). Unsur $P$ yang dilepaskan tersebut sebagian digunakan untuk pembentukan dan perkembangan simbiosis FMA karena FMA juga memerlukan P dalam jumlah tertentu (Smith \& Read, 2008). Ekskresi asam organik semakin berkurang jika umur tanaman bertambah sehingga simbiosis FMA harus ditingkatkan agar tamaman tetap mendapatkan $\mathrm{P}$ dari bentuk-bentuk yang tidak mudah tersedia. Hal tersebut ditunjukkan dengan rendahnya kolonisasi FMA pada umur 6 MST namun meningkat terus sampai umur 12 MST jika $P$. phaseoloides dipasok dengan bahan bio-anorganik (Tabel 3). Pembentukan simbiosis FMA memerlukan pengorbanan karbon hasil fotosintesis yang diperlukan untuk pembentukan biomassa tanaman. Tanaman yang bersimbiosis dengan FMA tidak selalu mendapatkan keuntungan dalam bentuk peningkatan biomassa namun dapat berupa peningkatan ketahanan cekaman biotik dan abiotik (Smith

Tabel 2. Rataan bobot kering (mg) akar dan pucuk tanaman P. phaseoloides umur 12 MST (minggu setelah tanam) setelah inokulasi FMA dan pemberian bahan bio-anorganik

\begin{tabular}{|c|c|c|c|c|}
\hline \multirow{2}{*}{ Bahan bio-anorganik } & \multicolumn{2}{|c|}{ Bobot kering akar } & \multicolumn{2}{|c|}{ Bobot kering pucuk } \\
\hline & Gle & Act & Gle & Act \\
\hline Kontrol & $42,43 \pm 3,42^{\text {defg }}$ & $23,93 \pm 3,51^{\mathrm{h}}$ & $170,00 \pm 11,56^{\text {efgh }}$ & $152,77 \pm 10,71^{\text {fgh }}$ \\
\hline SP36 & $80,77 \pm 4,60^{\mathrm{a}}$ & $38,20 \pm 4,42^{g}$ & $374,63 \pm 39,20^{\mathrm{a}}$ & $157,13 \pm 35,71^{\text {fgh }}$ \\
\hline BP $38,12 \mathrm{mg}$ & $55,37 \pm 3,94^{\mathrm{bcd}}$ & $42,57 \pm 5,57^{\text {defg }}$ & $158,07 \pm 3,74^{\mathrm{fgh}}$ & $137,87 \pm 15,96^{\mathrm{gh}}$ \\
\hline BP 76,23 mg & $57,53 \pm 7,90^{\mathrm{bc}}$ & $45,50 \pm 7,50^{\text {cdef }} g$ & $209,80 \pm 19,10^{\text {cdef }}$ & $179,67 \pm 22,96^{\mathrm{efg}}$ \\
\hline TTB $10,82 \mathrm{mg}$ & $38,73 \pm 8,27^{\mathrm{fg}}$ & $25,07 \pm 3,81^{\mathrm{hc}}$ & $127,10 \pm 5,07^{\mathrm{h}}$ & $100,40 \pm 33,86^{\mathrm{i}}$ \\
\hline TTB 21,65 mg & $51,37 \pm 6,80^{\text {bcdef }}$ & $58,73 \pm 8,21^{\mathrm{bc}}$ & $229,10 \pm 5,35^{\text {bcde }}$ & $165,33 \pm 15,84^{\mathrm{fgh}}$ \\
\hline TTG 11,85 mg & $54,37 \pm 7,95^{\text {bcde }}$ & $41,60 \pm 9,74^{\mathrm{efg}}$ & $201,47 \pm 17,38^{\text {def }}$ & $276,37 \pm 41,96^{\text {abcd }}$ \\
\hline TTG 23,70 mg & $61,83 \pm 12,72^{\mathrm{b}}$ & $63,63 \pm 9,28^{b}$ & $285,67 \pm 48,28^{\mathrm{abc}}$ & $298,40 \pm 30,93^{\mathrm{ab}}$ \\
\hline Jenis FMA & \multicolumn{2}{|c|}{$\mathrm{p}=0,0000$} & \multicolumn{2}{|c|}{$\mathrm{p}=0,0007$} \\
\hline Bahan bio-anorganik & \multicolumn{2}{|c|}{$p=0,0000$} & \multicolumn{2}{|c|}{$\mathrm{p}=0,0000$} \\
\hline Interaksi & \multicolumn{2}{|c|}{$p=0,0003$} & \multicolumn{2}{|c|}{$p=0,0005$} \\
\hline KK $(\%)$ & \multicolumn{2}{|c|}{3} & \multicolumn{2}{|c|}{3} \\
\hline
\end{tabular}

Keterangan: superskrip berbeda pada baris dan kolom yang sama menunjukkan berbeda nyata $(\mathrm{P}<0,05)$. Gle $=\mathrm{G}$. etunicatum, Act $=$ A. tuberculata, SP36= superfosfat $(36 \% \mathrm{P}), \mathrm{BP}=$ batuan fosfat, $\mathrm{TTB}=$ tepung tulang bakar, TTG= tepung tulang giling, FMA= fungi mikoriza arbuskula, $\mathrm{KK}=$ koefisien keragaman. 
\& Read, 2008). Penggunaan sumber P tidak mudah larut pada dasarnya tidak ditujukan untuk meningkatkan pertumbuhan tanaman sedini mungkin, namun lebih ditujukan untuk pemeliharaan kadar $\mathrm{P}$ dalam media untuk jangka panjang (Uusitalo et al., 2007) sehingga hanya sesuai untuk memproduksi inokulan FMA dalam jangka panjang.

\section{Kolonisasi dan Jumlah Spora FMA}

Jenis FMA, bahan bio-anorganik, dan interaksi keduanya berpengaruh sangat nyata $(\mathrm{P}<0,01)$ terhadap kolonisasi FMA pada akar P. phaseoloides umur 6 dan 12 MST dan jumlah spora pada medium tumbuh P. phaseoloides umur 12 MST (Tabel 3). Hal tersebut menunjukkan biologi FMA, khususnya kolonisasi dan pembentukan spora, ditentukan oleh jenis FMA dan sumber hara yang digunakan. Kolonisasi FMA yang tinggi pada umur 6 MST dihasilkan oleh G. etunicatum pada tanaman $P$. phaseoloides yang dipasok pupuk Hyponex merah (kontrol) atau SP36.

Pemberian pupuk dalam bentuk mudah larut (Hyponex merah atau SP36) dan tidak mudah larut (bahan bio-anorganik) ternyata menghasilkan kolonisasi oleh $A$. tuberculata yang lebih rendah dibandingkan $G$. etunicatum pada umur 6 MST. Respon tersebut kemudian berubah pada umur 12 MST, pupuk Hyponex merah (kontrol) dan bahan bio-anorganik kecuali batuan fosfat dosis 76,23 mg menghasilkan kolonisasi G. etunicatum yang tinggi $(>75 \%)$ namun hanya batuan fosfat dosis 76,23 mg yang menghasilkan kolonisasi A. tuberculata yang tergolong tinggi ( $>75 \%)$. Pemberian SP36 justru menekan kolonisasi G. etunicatum dan A. tuberculata.

Lebih tingginya kolonisasi FMA pada akar P. phaseoloides yang dipasok pupuk Hyponex merah disebabkan pupuk ini mengandung unsur $\mathrm{N}$ yang jauh lebih tinggi namun dengan kadar $\mathrm{P}$ yang rendah. Unsur $\mathrm{N}$ dilaporkan meningkatkan jumlah runner hifa, percabangan hifa untuk penyerapan, dan jumlah spora (Bago et al., 2004). Kolonisasi FMA mencapai maksimum jika tanaman inang ditumbuhkan pada tanah yang mengalami defisiensi hara P (Feldmann et al., 2009). Setiap jenis FMA berbeda responnya terhadap kadar $\mathrm{P}$ yang tinggi, perkecambahan spora G. etunicatum tidak dipengaruhi oleh kadar $\mathrm{P}$ tinggi namun sporulasinya berkorelasi positif dengan kadar hara P (Carrenho et al., 2001). Bahan yang berkadar $\mathrm{P}$ tinggi dengan kelarutan yang rendah, misalnya tepung tulang, juga meningkatkan persistensi propagul G. etunicatum dalam tanah berbahan induk abu vulkan (Rubio et al., 2003). Peningkatan pasokan N pada medium berkadar $\mathrm{P}$ rendah dilaporkan meningkatkan alokasi karbon yang diperlukan untuk pembentukan hifa ekstraradikal dan spora FMA jenis Glomus (Johnson et al., 2003). Namun demikian mekanismenya pada $A$. tuberculata masih belum diketahui dengan baik.

Penelitian sebelumnya menunjukkan kolonisasi A. tuberculata pada akar P. phaseoloides umur 12 MST mencapai $71 \%$ dan mencapai maksimal $99 \%$ pada umur 20 MST jika dipasok dengan larutan Hyponex merah (Chalimah et al., 2007). Widiastuti \& Suharyanto (2007) melaporkan bahwa kolonisasi $A$. tuberculata pada akar $C$. caeruleum dan C. pubescens umur 12 MST masing-masing mencapai $73 \%$ dan $70 \%$ pada penelitian yang menggunakan medium tumbuh campuran tanah dan pasir $(2: 1$ $\mathrm{b}$ /b) dan pupuk berupa larutan hara Johnson. Informasi demikian mengindikasikan bahwa G. etunicatum memiliki preferensi pupuk yang lebih banyak dibandingkan A. tuberculata. Tepung tulang yang memiliki nisbah NP yang rendah namun mengandung unsur mikro yang $\mathrm{cu}-$ kup tinggi tampaknya lebih cocok untuk perkembangan G. etunicatum dibandingkan $A$. tuberculata.

Tabel 3. Rataan kolonisasi mikoriza pada umur 6 dan 12 MST (minggu setelah tanam) dan jumlah spora per $100 \mathrm{~g}$ media tumbuh $P$. phaseoloides umur 12 MST

\begin{tabular}{|c|c|c|c|c|c|c|}
\hline \multirow{2}{*}{ Bahan bio-anorganik } & \multicolumn{2}{|c|}{ Kolonisasi 6 MST (\%) } & \multicolumn{2}{|c|}{ Kolonisasi 12 MST (\%) } & \multicolumn{2}{|c|}{ Jumlah spora (buah) } \\
\hline & Gle & Act & Gle & Act & Gle & Act \\
\hline Kontrol & $39 \pm 3^{a}$ & $15 \pm 1^{\mathrm{bcd}}$ & $99 \pm 1^{\mathrm{a}}$ & $75 \pm 11^{\text {bcde }}$ & $715 \pm 208^{\mathrm{cd}}$ & $43 \pm 11^{\mathrm{h}}$ \\
\hline SP36 & $26 \pm 2^{\mathrm{ab}}$ & $5 \pm 1^{\text {ef }}$ & $32 \pm 11^{g}$ & $26 \pm 5^{g}$ & $237 \pm 134^{\text {def }}$ & $85 \pm 37^{\text {fgh }}$ \\
\hline BP 38,12 mg & $13 \pm 3^{\text {bcde }}$ & $8 \pm 1^{\mathrm{cdf}}$ & $88 \pm 4^{\mathrm{ab}}$ & $61 \pm 12^{\text {ef }}$ & $649 \pm 214^{c}$ & $51 \pm 36^{\mathrm{gh}}$ \\
\hline BP 76,23 mg & $8 \pm 1^{\mathrm{ce}}$ & $13 \pm 2^{\text {bcde }}$ & $72 \pm 2^{\text {cde }}$ & $80 \pm 3^{\mathrm{bcd}}$ & $251 \pm 87^{\text {defg }}$ & $50 \pm 20^{\text {gh }}$ \\
\hline TTB $10,82 \mathrm{mg}$ & $12 \pm 2^{\mathrm{df}}$ & $6 \pm 2^{\mathrm{ef}}$ & $77 \pm 2^{\text {bcd }}$ & $37 \pm 13^{g}$ & $112 \pm 68^{\mathrm{fgh}}$ & $173 \pm 134^{\mathrm{eh}}$ \\
\hline TTB 21,65 mg & $12 \pm 2^{\text {cde }}$ & $5 \pm 2^{\text {ef }}$ & $89 \pm 2^{\mathrm{ab}}$ & $56 \pm 9^{f}$ & $1708 \pm 628^{\mathrm{ab}}$ & $396 \pm 128^{\text {ce }}$ \\
\hline TTG $11,85 \mathrm{mg}$ & $17 \pm 5^{\text {bc }}$ & $8 \pm 1^{\text {cdef }}$ & $85 \pm 7^{\mathrm{abc}}$ & $69 \pm 8^{\text {def }}$ & $1578 \pm 663^{\mathrm{ab}}$ & $63 \pm 44^{\text {fgh }}$ \\
\hline TTG 23,70 mg & $19 \pm 7^{\mathrm{bc}}$ & $3 \pm 2^{f}$ & $96 \pm 5^{\mathrm{a}}$ & $73 \pm 9^{\text {bcde }}$ & $2212 \pm 162^{\mathrm{a}}$ & $789 \pm 246^{\mathrm{bc}}$ \\
\hline Jenis FMA & \multicolumn{2}{|c|}{$p=0,0000$} & \multicolumn{2}{|c|}{$\mathrm{p}=0,0000$} & \multicolumn{2}{|c|}{$\mathrm{p}=0,0000$} \\
\hline Bahan bioanorganik & \multicolumn{2}{|c|}{$\mathrm{p}=0,0008$} & \multicolumn{2}{|c|}{$\mathrm{p}=0,0000$} & \multicolumn{2}{|c|}{$\mathrm{p}=0,0000$} \\
\hline Interaksi & \multicolumn{2}{|c|}{$p=0,0100$} & \multicolumn{2}{|c|}{$\mathrm{p}=0,0004$} & \multicolumn{2}{|c|}{$\mathrm{p}=0,0011$} \\
\hline KK (\%) & \multicolumn{2}{|c|}{10} & \multicolumn{2}{|c|}{12} & \multicolumn{2}{|c|}{15} \\
\hline
\end{tabular}

Keterangan: superskrip berbeda pada baris dan kolom yang sama menunjukkan berbeda nyata $(\mathrm{P}<0,05)$. Gle= G. etunicatum, Act $=$ A. tuberculata, SP36= superfosfat $(36 \% \mathrm{P}), \mathrm{BP}=$ batuan fosfat, $\mathrm{TTB}=$ tepung tulang bakar, $\mathrm{TTG}=$ tepung tulang giling, FMA= fungi mikoriza arbuskula, $\mathrm{KK}=$ koefisien keragaman. 
Jumlah spora merupakan indikator potensi inokulum yang paling mudah diukur. Berkebalikan dengan pengaruhnya terhadap kolonisasi akar, tepung tulang menghasilkan spora yang lebih banyak dibandingkan kontrol dan SP36. Tepung tulang bakar dosis 21,65 $\mathrm{mg}$, tepung tulang giling dosis $11,85 \mathrm{mg}$ dan $23 \mathrm{mg}$ masing-masing menghasilkan spora $G$. etunicatum sebanyak 1708, 1578 dan 2212 buah. Jumlah tersebut sekitar 2-3 kali lebih tinggi dibandingkan dengan jumlah spora yang dihasilkan oleh perlakuan kontrol yang menghasilkan spora sebanyak 715 buah. Jumlah spora A. tuberculata lebih sedikit dibandingkan dengan $G$. etunicatum sekalipun mendapatkan sumber hara yang sama. Hyponex merah (kontrol) menghasilkan spora $A$. tuberculata sebanyak 43 buah, sedangkan tepung tulang bakar dosis 10,82 $\mathrm{mg}$ dan 21,65 $\mathrm{mg}$ dan tepung tulang giling dosis 23,70 mg masing-masing menghasilkan spora A. tuberculata sebanyak 173, 396, dan 789 buah.

Spora FMA terbentuk dari ujung hifa ekstraradikal yang menggelembung dan kemudian terlepas dari hifa ekstraradikal tersebut (Smith \& Read, 2008). Hifa FMA merupakan wahana perpindahan karbon dari tanaman dan hara dari dalam tanah. Hifa tersebut terbagi menjadi dua, yaitu hifa intraradikal yang terdapat di dalam akar dan hifa ekstraradikal yang terbentuk dari hifa intraradikal yang menjulur keluar dari akar dan membentuk percabangan yang ekstensif di rhizosfir tanaman. Semakin banyak hifa ekstraradikal berpotensi meningkatkan pembentukan spora bergantung kepada jenis FMA dan faktor luar seperti pasokan karbon dan ketersediaan hara. G. etunicatum memiliki diameter hifa intraradikal yang lebih besar $(2,2-18,0 \mu \mathrm{m})$, jumlahnya banyak dan menyebar pada seluruh akar namun hifa ekstraradikalnya berkembang lambat dan tidak ekstensif dan sebaliknya dengan $A$. tuberculata yang diameter hifa intraradikalnya lebih kecil $(1,2-9,1 \mu \mathrm{m})$, jumlahnya lebih sedikit, dan sebarannya juga tidak merata pada akar namun hifa ekstraradikalnya lebih cepat berkembang dan tersebar ekstensif di sekitar permukaan akar (Dodd et al., 2000; Smith \& Read, 2008).

Spora G. etunicatum NPI-126 memiliki rataan ukuran diameter $140 \mu \mathrm{m}$ sedangkan spora $A$. tuberculata INDO-2 memiliki rataan diameter $295 \mu \mathrm{m}$. Karena volume sporanya yang lebih besar, A. tuberculata memerlukan lebih banyak karbon dan unsur hara dibandingkan dengan G. etunicatum. Tanaman dapat mengalokasikan sekitar 20\% karbon hasil fotosintesisnya untuk pembentukan simbiosis MA (Smith \& Read, 2008). Tanaman $P$. phaseoloides yang dikolonisasi G. etunicatum memiliki biomassa yang lebih tinggi dibandingkan dengan yang dikolonisasi $A$. tuberculata jika dipasok dengan sumber hara yang sama (Tabel 2), sehingga memungkinkan mengalokasikan karbon yang lebih banyak ke FMA. Oleh sebab itu, G. etunicatum membentuk spora yang lebih banyak sekalipun berukuran lebih kecil dibandingkan dengan A. tuberculata.

Lebih lambatnya penyediaan $\mathrm{P}$ oleh bahan bioanorganik, khususnya tepung tulang giling, cocok bagi pembentukan dan perkembangan hifa ekstraradikal $G$. etunicatum yang bersifat lebih lambat dibandingkan $A$. tuberculata. Namun demikian bukan berarti bahwa pupuk mudah larut, misalnya SP36 dan Hyponex merah, yang cepat menyediakan $\mathrm{P}$ cocok untuk pembentukan spora $A$. tuberculata yang perkembangan hifa ekstraradikalnya ekstensif dan cepat. Hal tersebut disebabkan pembentukan spora atau sporulasi $A$. tuberculata pada dasarnya lebih lambat atau jumlah sporanya ditentukan oleh waktu (Bertham, 2003; Chalimah et al., 2007). Informasi demikian dapat digunakan untuk menjelaskan lebih banyaknya spora G. etunicatum pada umur 12 MST pada medium tumbuh yang dipasok dengan batuan fosfat dan tepung tulang (Tabel 3). Pasokan karbon, hara, dan waktu yang lebih lama diperlukan untuk menghasilkan jumlah spora $A$. tuberculata yang sama banyaknya dengan G. etunicatum.

\section{KESIMPULAN}

Bahan bio-anorganik dapat digunakan sebagai pupuk untuk meningkatkan pembentukan biomassa legum pakan $P$. phaseoloides dan memproduksi inokulan FMA. Hijauan pakan P. phaseoloides akan menghasilkan biomassa yang tinggi jika diinokulasi dengan G. etunicatum dan diberi pupuk SP36. Tepung tulang giling dosis $11,85 \mathrm{mg}$ /pot merupakan sumber hara terbaik untuk memproduksi inokulan FMA G. etunicatum, ditinjau dari kolonisasi akar dan jumlah spora, menggunakan hijauan pakan $P$. phaseoloides sebagai inang.

\section{UCAPAN TERIMA KASIH}

Ucapan terima kasih disampaikan kepada Direktorat Jenderal Pendidikan Tinggi Kementerian Pendidikan Nasional Republik Indonesia yang telah memberikan beasiswa BPPS kepada penulis pertama untuk mengikuti program S3 pada Sekolah Pascasarjana Institut Pertanian Bogor.

\section{DAFTAR PUSTAKA}

Bago, B., C. Cano, C. Azcon-Aguilar, J. Samson, A. P. Coughlan, \& Y. Piche. 2004. Differential morphogenesis of the extraradical mycelium of an arbuscular mycorrhizal fungus grown monoxenically on spatially heterogeneous culture media. Mycologia 96: 452-462.

Bertham, Y. H. 2003. Tehnik pemurnian biakan monoxenic CMA dengan metode cawan petri dan tabung reaksi. Jurnal Ilmu-Ilmu Pertanian Indonesia 5: 18-26.

Carrenho, R., E. S. Silva, S. F. B. Trufem, \& V. L. R. Bononi. 2001. Succesive cultivation of maize and agricultural practices on root colonization, number of spores and species of AM fungi. Braz. J. Microbiol. 32: 262-270.

Chalimah, S., Muhadiono, L. Aznam, S. Haran, \& N. ToruanMathius. 2007. Perbanyakan Gigaspora sp. dan Acaulospora sp. dengan kultur pot di rumah kaca. Biodiversitas 7: $12-19$.

Dodd, J. C., C. L. Boddington, A. Rodriguez, C. GonzalezChavez, \& I. Mansur. 2000. Mycelium of arbuscular mycorrhizal fungi (AMF) from different genera: form, function and detection. Plant Soil 226: 131-151.

Feldmann, F., I. Hutter, \& C. Schneider. 2009. Best production practice of arbuscular mycorrhizal inoculum. Soil Biol. 18: 319-335.

Biofertilizer Project Group. 2006. Biofertilizer Manual. Forum for Nuclear Cooperation in Asia, Japan Atomic Industrial Forum, Tokyo.

Hart, M. M. \& R. J. Reader. 2002. Host plant benefit from as- 
sociation with arbuscular mycorrhizal fungi: variation due to differences in size of mycelium. Biol. Fertil. Soils 36: 357-366.

Jeng, A. S., T. K. Haraldsen, A. Gronlund, \& P. A. Pedersen. 2006. Meat and bone meal as nitrogen and phosphorus fertilizer to cereals and rye grass. Nutr. Cycl. Agron. 76: 183-191.

Johnson, N. C., D. L. Rowland, L. Corkidi, L. M. EgertonWarburton, \& E. B. Allen. 2003. Nitrogen enrichment alters mycorrhizal allocation at five mesic to semiarid grasslands. Ecology 84: 1895-1908.

Karti, P. D. M. H. 2004. Pengaruh pemberian cendawan mikoriza arbuskula terhadap pertumbuhan dan produksi rumput Setaria splendida Stapf yang mengalami cekaman kekeringan. Med. Pet. 27: 63-68.

Lukiwati, D. R. 2007. Dry matter production and digestibility Improvement of Centrosema pubescens and Pueraria phaseoloides with rock phosphate fertilization and VAM inoculation. Jurnal Ilmu-Ilmu Pertanian Indonesia 9: 1-5

Mayerni, R. \& D. Hervani. 2008. Pengaruh jamur mikoriza arbuskula terhadap pertumbuhan tanaman selasih (Ocium sanctum L.). Jurnal Akta Agrosia 11: 7-13.

Nikolaou, N., N. Karagiannidis, S. Koundouras, \& I. Fysarakis. 2002. Effects of different P sources in soil on increasing growth and mineral uptake of mycorrhizal
Vitis vinifera L. (cv Victoria) vines. J. Int. Sci. Vigne. Vin 36: 195-204.

Romer, W. 2006. Plant availability of $\mathrm{P}$ from recycling products and phosphate fertilizers in a growth-chamber trial with rye seedlings. J. Plant. Nutr. Soil Sci. 169: 826-832.

Rubio, R., F. Borie, C. Schalchli, C. Castillo, \& R. Azcon. 2003. Occurrence and effect of arbuscular mycorrhizal propagules in wheat as affected by the source and amount of phosphorus fertilizer and fungal inoculation. Appl. Soil Ecol. 23: 245-255.

Smith, S. E. \& D. J. Read. 2008. Mycorrhizal Symbiosis. $3^{\text {rd }}$ ed. Academic Press, San Diego.

Uusitalo, R., K. Ylivainio, E. Turtola, \& A. Kangas. 2007. Accumulation and translocation of sparsely soluble manure phosphorus in different types of soils after long-term excessive inputs. Agric. Food Sci. 16: 317-331.

Warren, G. P., J. S. Robinson, \& E. Someus. 2009. Dissolution of phosphorus from animal bone char in 12 soils. Nutr. Cycl. Agroecosyst. 84: 167-178.

Widiastuti, H. \& Suharyanto. 2007. Growth response of Calopogonium caeruleum and Centrosema pubescens ground cover crops toward inoculation of Bradyrhizobium, Aeromonas punctata, and Acaulospora tuberculata. Buletin Plasma Nutfah 13: 43-48. 